NASA/TM-2000-209891, Vol. 64

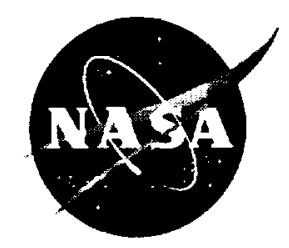

Technical Report Series on the Boreal Ecosystem-Atmosphere Study (BOREAS)

Forrest G. Hall and Jaime Nickeson, Editors

Volume 64

BOREAS RSS-14 Level-3 Gridded Radiometer and Satellite Surface Radiation Images

G. Hodges and E.A. Smith

National Aeronautics and

Space Administration

Goddard Space Flight Center

Greenbelt, Maryland 20771 


\section{The NASA STI Program Office ... in Profile}

Since its founding, NASA has been dedicated to the advancement of aeronautics and space science. The NASA Scientific and Technical Information (STI) Program Office plays a key part in helping NASA maintain this important role.

The NASA STI Program Office is operated by Langley Research Center, the lead center for NASA's scientific and technical information. The NASA STI Program Office provides access to the NASA STI Database, the largest collection of aeronautical and space science STI in the world. The Program Office is also NASA's institutional mechanism for disseminating the results of its research and development activities. These results are published by NASA in the NASA STI Report Series, which includes the following report types:

- TECHNICAL PUBLICATION. Reports of completed research or a major significant phase of research that present the results of NASA programs and include extensive data or theoretical analysis. Includes compilations of significant scientific and technical data and information deemed to be of continuing reference value. NASA's counterpart of peer-reviewed formal professional papers but has less stringent limitations on manuscript length and extent of graphic presentations.

- TECHNICAL MEMORANDUM. Scientific and technical findings that are preliminary or of specialized interest, e.g., quick release reports, working papers, and bibliographies that contain minimal annotation. Does not contain extensive analysis.

- CONTRACTOR REPORT. Scientific and technical findings by NASA-sponsored contractors and grantees.
- CONFERENCE PUBLICATION. Collected papers from scientific and technical conferences, symposia, seminars, or other meetings sponsored or cosponsored by NASA.

- SPECIAL PUBLICATION. Scientific, technical, or historical information from NASA programs, projects, and mission, often concerned with subjects having substantial public interest.

- TECHNICAL TRANSLATION.

English-language translations of foreign scientific and technical material pertinent to NASA's mission.

Specialized services that complement the STI Program Office's diverse offerings include creating custom thesauri, building customized databases, organizing and publishing research results ... even providing videos.

For more information about the NASA STI Program Office, see the following:

- Access the NASA STI Program Home Page at http://www.sti.nasa.gov/STI-homepage.html

- E-mail your question via the Internet to help@sti.nasa.gov

- Fax your question to the NASA Access Help Desk at (301) 621-0134

- Telephone the NASA Access Help Desk at (301) 621-0390

- Write to: NASA Access Help Desk NASA Center for AeroSpace Information 7121 Standard Drive Hanover, MD 21076-1320 
NASA/TM-2000-209891, Vol. 64

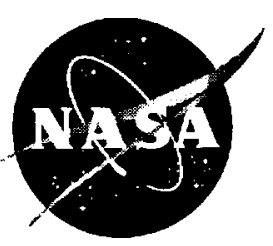

Technical Report Series on the Boreal Ecosystem-Atmosphere Study (BOREAS)

Forrest G. Hall and Jaime Nickeson, Editors

\section{Volume 64}

\section{BOREAS RSS-14 Level-3 Gridded Radiometer and Satellite Surface Radiation Images}

Gary Hodges and Eric A. Smith, Florida State University

National Aeronautics and

Space Administration

Goddard Space Flight Center

Greenbelt, Maryland 20771 
Available from:

NASA Center for AeroSpace Information

7121 Standard Drive

Hanover, MD 21076-1320

Price Code: A17
National Technical Information Service 5285 Port Royal Road Springfield, VA 22161

Price Code: A10 


\title{
BOREAS RSS-14 Level-3 Gridded Radiometer and Satellite Surface Radiation Images
}

\author{
Gary B. Hodges, Eric A. Smith
}

\section{Summary}

The BOREAS RSS-14 team collected and processed GOES-7 and -8 images of the BOREAS region as part of its effort to characterize the incoming, reflected, and emitted radiation at regional scales. This data set contains surface radiation parameters, such as net radiation and net solar radiation, that have been interpolated from GOES-7 images and AMS data onto the standard BOREAS mapping grid at a resolution of $5 \mathrm{~km} \mathrm{~N}-\mathrm{S}$ and E-W. While some parameters are taken directly from the AMS data set, others have been corrected according to calibrations carried out during IFC-2 in 1994. The corrected values as well as the uncorrected values are included. For example, two values of net radiation are provided: an uncorrected value ( $\mathrm{Rn}$ ), and a value that has been corrected according to the calibrations ( $\mathrm{Rn}$-COR). The data are provided in binary image format data files.

Note: some of the data files on the BOREAS CD-ROMs have been compressed using the Gzip program. See section 8.2 for details.

\section{Table of Contents}
1) Data Set Overview
2) Investigator(s)
3) Theory of Measurements
4) Equipment
5) Data Acquisition Methods
6) Observations
7) Data Description
8) Data Organization
9) Data Manipulations
10) Errors
11) Notes
12) Application of the Data Set
13) Future Modifications and Plans
14) Software
15) Data Access
16) Output Products and Availability
17) References
18) Glossary of Terms
19) List of Acronyms
20) Document Information

\section{Data Set Overview}

\subsection{Data Set Identification}

BOREAS RSS-14 Level-3 Gridded Radiometer and Satellite Surface Radiation Images

\subsection{Data Set Introduction}

A gridded data set of various surface radiation parameters covering a large portion of the BOReal Ecosystem-Atmosphere Study (BOREAS) study area has been produced. Because surface net radiation is generally a main determinant of how the hydrometeorological system operates and how the phenology of a canopy functions, it is a fundamental quantity observed during BOREAS. The project 
that produced this data set was designed to ensure the highest possible accuracy and precision of the net radiation measurements taken throughout and between the BOREAS measurement sites. This project attempted to assess how well current geosynchronous satellite algorithms, based on two-channel Geosynchronous Operational Environmental Satellite (GOES)-7 visible radiance inputs, can help retrieve surface net radiation at a hierarchy of space and time scales (Hodges and Smith, 1997). All net radiation measurements incorporated in this objective analysis from the multiple sites have been intercalibrated to an Eppley four-way directional pyranometer/pyrgeometer system, for which the calibrations are traceable to the primary radiometer standard maintained at the Davos, Switzerland, World Radiation Centre, which is calibrated on the World Radiometric Reference (WRR) scale. The radiometers used in the field were cross calibrated at a common site prior to the onset of the 1994 BOREAS summer field phase. All operational flux stations that used a net pyrradiometer in and between the Northern Study Area (NSA) and Southern Study Area (SSA) were visited for at least one complete solar cycle during the second Intensive Field Campaign (IFC-2) with one of three transfer net pyrradiometers to check on residual sensitivity differences. The transfer net pyrradiometers had been calibrated against the Eppley four-way system, and thus their role was to transfer the calibration of the Eppley system to the operational net pyrradiometers at each of the BOREAS flux measurement sites. While net radiation was the primary focus of the field phase as well as the post-field analysis, additional surface radiation parameters are also included in the data set.

\subsection{Objective/Purpose}

The primary objective of the field phase was to calibrate all the BOREAS operational net pyrradiometers to a single standard, which itself had been carefully calibrated, and to examine the spatial and temporal distribution of net radiation at different scales.

Previous experiments of varying scales have measured net radiation at multiple locations over an extended domain for surface energy balance research. Few of these have actually used net radiation data gathered at multiple sites to examine the spatial and temporal distribution of $\mathrm{Rn}$, and none have systematically addressed the nature of the underlying measurement biases obtained from different models of net radiation measuring devices. It had always been understood in these experiments that a certain degree of error permeated the Rn data sets, but followup reporting of such data sets has mostly considered intercalibration errors in anecdotal fashion, if at all. It is the intent of this study to focus on these differences and to assess distortions in the space-time net radiation field. This data set is an expanded version of the one used for the net radiation analysis (Hodges and Smith, 1997).

\subsection{Summary of Parameters and Variables}

Thirty-minute averages of surface radiation parameters have been interpolated onto the standard BOREAS mapping grid at a 5-km resolution (the grid covers both the NSA and the SSA as well as the transect between the two). This is a continuous data set starting on 16-May-1994 and ending on 20-September-1994 (Julian days 136 to 263 ).

The following surface radiation parameters are included:

- Scaled Uncorrected Net Surface Radiation

- Scaled Corrected Net Surface Radiation

- Scaled Shortwave down at surface

- Scaled Shortwave up at surface

- Scaled Net Shortwave at surface

- Scaled Uncorrected Longwave down at surface

- Scaled Corrected Longwave down at surface

- Scaled Uncorrected Longwave up at surface

- Scaled Uncorrected Net Longwave at surface

- Scaled Corrected Net Longwave at surface

- Scaled Uncorrected Combined Net Radiation at surface

- $\quad$ Scaled Corrected Combined Net Radiation at surface

- Scaled Optimal Net Radiation 


\title{
1.5 Discussion
}

During 1994's IFC-2, the Remote Sensing Science (RSS)-14 team leapfrogged three calibrated (calibrated to an Eppley four-way pyranometer-pyrgeometer system) pyrradiometers among all Automatic Meteorological Station (AMS) sites, calibrating the operational net pyrradiometer at each. (Note that this was also done at all the Tower Flux (TF) sites, but those calibrations, or TF data, are not part of this data set. See Hodges and Smith (1997) for more details on TF calibrations.) The AMS net radiation data were then corrected according to the site-specific calibrations. Additionally, the parameters net longwave radiation $\left(\mathrm{L}^{*}\right)$ and downwelling longwave radiation ( $\mathrm{L}_{-}$down) were extracted from the measurements of net radiation ( $\mathrm{Rn})$. When $\mathrm{Rn}$ was used to extract another parameter, both uncorrected and corrected values of $\mathrm{Rn}$ were used, which gave both an uncorrected and corrected value of the extracted variable. All the extracted parameters, along with those parameters that were directly measured (such as downwelling and reflected solar values), were then interpolated onto a grid to produce the data set.

\subsection{Related Data Sets}

BOREAS AFM-07 SRC Surface Meteorological Data

BOREAS RSS-14 Level-1 GOES-7 Visible, IR and Water-vapor Channel Images

BOREAS RSS-14 Level-1a GOES-7 Visible, IR, and Water-vapor Images

BOREAS RSS-14 Level-2 GOES-7 Shortwave Radiation Images

BOREAS RSS-14 Level-1 GOES-8 Visible, IR and Water-vapor Channel Images

BOREAS RSS-14 Level-1a GOES-8 Visible, IR, and Water-vapor Images

\section{Investigator(s)}

\subsection{Investigator(s) Name and Title}

Dr. Eric A. Smith, Professor

\subsection{Title of Investigation}

Quality Assurance of BOREAS Net Radiation Measurements

\subsection{Contact Information}

\section{Contact 1:}

Gary B. Hodges

NOAA/ERL/ARL/SRRB

$\mathrm{R} / \mathrm{E} / \mathrm{ARx} 1$

325 Broadway

Boulder CO 80303

(303) 497-6460

(303) 497-6546 (fax)

hodges@srrb.noaa.gov

\author{
Contact 2: \\ Dr. Eric A. Smith, Professor \\ Department of Meteorology \\ Florida State University \\ Tallahassee FL 32306-3034 \\ (850) 644-4253 \\ (850) 644-9639 (fax) \\ esmith@metsat.met.fsu.edu
}




\author{
Contact 3: \\ Jaime Nickeson \\ Raytheon ITSS \\ NASA GSFC \\ Code 923 \\ Greenbelt, MD 20771 \\ (301) 286-3373 \\ (301) 286-0239 (fax) \\ Jaime.Nickeson@gsfc.nasa.gov
}

\title{
3. Theory of Measurements
}

Because surface net radiation is generally a main determinant of how the hydrometeorological system operates and how the phenology of a canopy functions, it is a fundamental quantity observed during BOREAS. This project is designed to ensure the highest possible accuracy and precision of the net radiation measurements taken throughout and between the BOREAS measurement sites. This project attempts to assess how well current geosynchronous satellite algorithms, based on two-channel GOES visible radiance inputs, can help retrieve surface net radiation at a hierarchy of space and time scales. All net radiation measurements incorporated in the objective analysis from the multiple sites were intercalibrated to an Eppley four-way directional pyranometer/pyrgeometer system, for which the calibrations would be traceable to the primary radiometer standard maintained at the Davos, Switzerland, World Radiation Centre, which is calibrated on the WRR scale. All radiometers used in the field were cross calibrated at a common site prior to the onset of the 1994 BOREAS summer field phase. All net radiometer stations at and between the NSA and SSA were visited for at least one complete solar cycle during IFC-2 with one of three transfer net pyrradiometers to check on residual sensitivity differences. The transfer net pyrradiometers had been calibrated against the Eppley four-way system, and thus their role was to transfer the calibration of the Eppley system to the operational net pyrradiometers at each of the BOREAS flux measurement sites.

In short, gridded fields of net radiation (both corrected according to the site-specific calibrations and uncorrected) have been produced over a large-scale area encompassing the NSA, the SSA, and the transect between the two. Additionally, satellite-retrieved surface net shortwave radiation data were combined with surface net longwave radiation data extracted from the corrected and uncorrected net radiation measurements to produce satellite-based fields of net radiation. Finally, parameters from the AMS sites, including downwelling and reflected shortwave radiation and net longwave radiation, are also included.

\section{Equipment}

\subsection{Sensor/Instrument Description}

\subsubsection{Collection Environment}

For the calibrations, the goal was to collect at least one cloud-free solar cycle at each site, but because of time and travel constraints, this was not always possible. It is generally considered that very clear skies are required to produce the best calibrations, and while there is certainly some truth to that, in practice, it was found in this case that calibration differences between clear and cloudy skies were very small. All measurements were made outdoors in ambient weather conditions during July and August of 1994. 


\subsubsection{Source/Platform}

As mentioned in Section 4.1.1, the instruments were usually mounted on a tower, either a walk-up or climber, above the tree canopy. At two field/meadow and two fen sites, the instruments were mounted much closer to the ground. Care was taken to mount the transfer net pyrradiometers in very close to the operational instruments.

\subsubsection{Source/Platform Mission Objectives}

The objective of the main BOREAS TM and AMS towers was to provide a stable fixed location on which to mount various instruments for monitoring fluxes and meteorological conditions, respectively, at the BOREAS sites and across the BOREAS region.

\subsubsection{Key Variables}

The only variable actually measured by RSS-14 was net radiation; however, RSS-14 net radiation is not what is included in the data set. The BOREAS operational net pyrradiometers were only calibrated by RSS-14. This data set includes, among other variables, corrected net radiation according to those correction factors found during the calibrations. The following is a list of the variables included in this data set (all are direct AMS measurements, corrected AMS measurements, or extracted from AMS measurements):

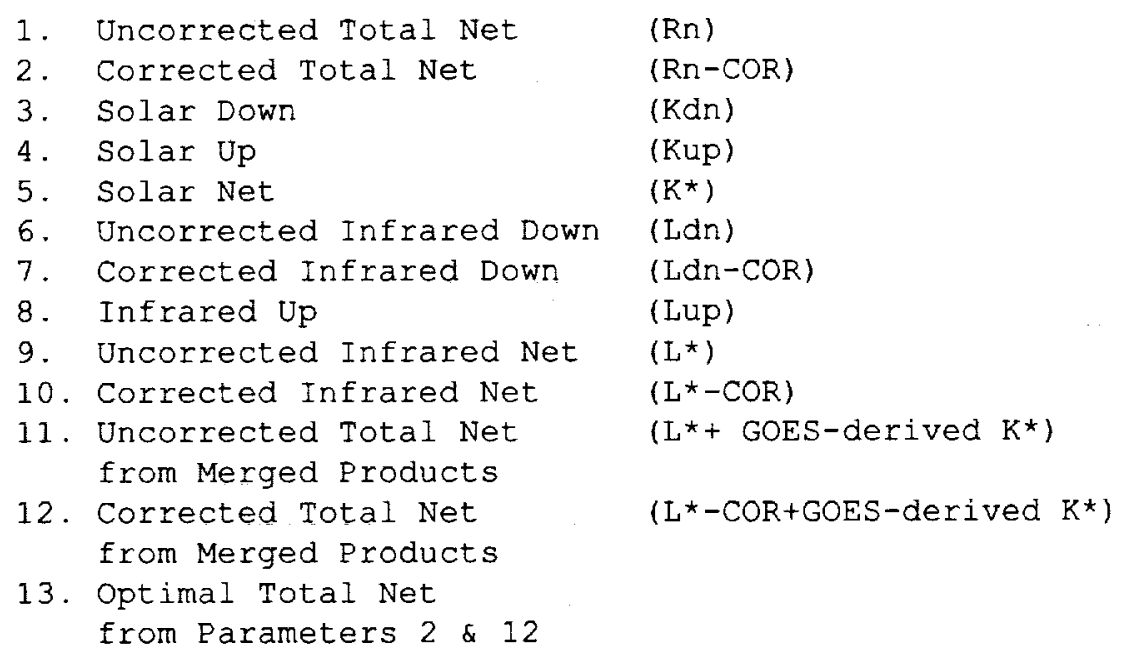

\subsubsection{Principles of Operation}

All the radiometers incorporate a thermopile design to estimate irradiance intensities. Basically, the output of the thermopile is proportional to the intensity, so that the output voltage can be multiplied by a constant (a sensitivity coefficient) to give an irradiance value.

\subsubsection{Sensor/Instrument Measurement Geometry}

Net pyrradiometers, for obvious reasons, require as unobstructed a view as possible both above and below the instrument. This is "as possible" because the instrument has to be mounted on something, which invariably obstructs the view to some extent. For upfacing pyranometers (or pyrgeometers), it is easily possible to mount them such that there are no obstructions above the plane of the instrument. These same instruments mounted in a downfacing position have similar view problems/issues as the net pyrradiometer. Pyranometers and pyrgeometers have a 180-degree field of view, while a net pyrradiometer has a 360-degree field of view (180 × 2). 


\subsubsection{Manufacturer of Sensor/Instrument \\ Q*6 Net Pyrradiometer \\ Radiation and Energy Balance Systems, Inc.}

P.O. Box 15512

Seattle, WA 98115-0512

(206) 624-7221 (fax)

(206) 228-4067

Eppley Instruments (PSP, PIR, Everest 4000)

The Eppley Laboratory, Inc.

12 Sheffield Avenue

P.O. Box 419

Newport, RI 02840

(401) 847-1020 (fax)

(401) $847-1031$

\subsection{Calibration}

Three new net pyrradiometers were purchased for this study, known as the "transfer radiometers." These three instruments were calibrated against a four-way pyranometer/pyrgeometer system. One pyranometer and one pyrgeometer were sent to The Eppley Labs for calibration. The other pyranometer and pyrgeometer were then calibrated against the first two.

\subsubsection{Specifications}

- Eppley Labs Precision Spectral Pyranometer model PSP

- Eppley Labs Precision Infrared Radiometer model PIR

- Eppley Labs Infrared Thermometer (IRT), Everest model 4000

- $\quad$ Radiation and Energy Balance Systems (REBS), Inc., Net Pyrradiometer model Q*6

The Eppley PSP measures shortwave radiation in the spectral sensitivity range of 0.285 to 2.8 microns, and the Eppley PIR measures longwave, or terrestrial, radiation in the spectral range of 3.5 to 50 microns. Both the PSP and the PIR can be mounted in either an upfacing or a downfacing position to measure downwelling or upwelling fluxes. The Everest model 4000 measures the surface temperature, which can then be converted to irradiance by the Stefan-Boltzmann law. The Q*6 measures net radiation in the spectral range of 0.25 to 60 microns.

Note: RSS-14 used three $Q * 6$ instruments to calibrate the operational instruments. The $Q^{*} 6$ 's were calibrated prior to and after being in the field with a four-way system consisting of two PIR/PSP pairs. The data contained in this data set were ALL collected with the above types of instruments located at the AMS sites, NOT with RSS-14 instruments. The RSS-14 net pyrradiometers were used solely for calibration purposes. The calibration process and results are discussed in detail in Hodges and Smith (1997).

\subsubsection{Tolerance}

It is not possible to state the accuracy of the measurements, i.e., how accurate the between-site gradients of net radiation are. In the end, the final accuracy will likely be determined by modelers who are using these data between sites.

Instrument sensitivity:

REBS Q*6 Sensitivity is listed as $0.0775 \mathrm{mV} / \mathrm{W} / \mathrm{m}^{2}$ Eppley PSP Sensitivity is listed as $0.0009 \mathrm{mV} / \mathrm{W} / \mathrm{m}^{2}$ Eppley PIR Sensitivity is listed as $0.0004 \mathrm{mV} / \mathrm{W} / \mathrm{m}^{2}$

\subsubsection{Frequency of Calibration}

Pre- and post-field calibrations were performed on the instruments RSS-14 took into the field. These calibrations were approximately 5 months apart. 


\subsubsection{Other Calibration Information}

The instruments used were not modified in any way.

\section{Data Acquisition Methods}

Data were collected in situ. At each of the 10 AMS sites, one net pyrradiometer was operated. The calibrated net pyrradiometer (see Section 3 ) was run alongside each operational net pyrradiometer. Most of the instruments were located above the canopy on a tower, but a few sites were in fields or fens where the instrument was located close to the ground. The BOREAS Experiment Plan provides good descriptions of the characteristics of each site.

For the calibrations, the goal was to collect at least one cloud-free solar cycle at each site, but because of time and travel constraints, this was not always possible. It is generally considered that very clear skies are required to produce the best calibrations, and while there is certainly some truth to that, in practice, it was found in this case that calibration differences between clear and cloudy skies were very small.

RSS-14 used Campbell Scientific $21 \mathrm{X}$ data loggers to record the net radiation measured. The transfer net pyrradiometers were colocated with the operational instruments.

\section{Observations}

\subsection{Data Notes}

The goal was to measure at least one complete cloud-free solar cycle at each site. This goal was not attainable at every site. An analysis of cloudy skies on calibration was performed, and it was found that for this calibration approach, clouds had a negligible effect. Efforts to use only the most cloud-free periods from each site were made nonetheless.

\subsection{Field Notes}

None given.

\section{Data Description}

\subsection{Spatial Characteristics}

\subsubsection{Spatial Coverage}

A parallelogram comprises the extent of the spatial coverage. This area was chosen such that no portion of the parallelogram extended very far outside the domain of the AMS network. (To include the northwest portion of the NSA, it was necessary to extend the parallelogram beyond the AMS network's domain.) The spatial coverage of this data set is a parallelogram with the comers:

\begin{tabular}{lcccc} 
& Latitude & \multicolumn{1}{c}{ Longitude } & BOREAS X & BOREAS Y \\
$\mathrm{NW}$ & $56.57772^{\circ} \mathrm{N}$ & $101.60420^{\circ} \mathrm{W}$ & 575 & 660 \\
$\mathrm{NE}$ & $55.96247^{\circ} \mathrm{N}$ & $95.47948^{\circ} \mathrm{W}$ & 960 & 660 \\
$\mathrm{SW}$ & $53.43708^{\circ} \mathrm{N}$ & $108.13830^{\circ} \mathrm{W}$ & 190 & 275 \\
$\mathrm{SE}$ & $53.15204^{\circ} \mathrm{N}$ & $102.37890^{\circ} \mathrm{W}$ & 575 & 275
\end{tabular}




\subsubsection{Spatial Coverage Map}

The following figure shows the boundaries of the BOREAS region and the area used for this analysis.

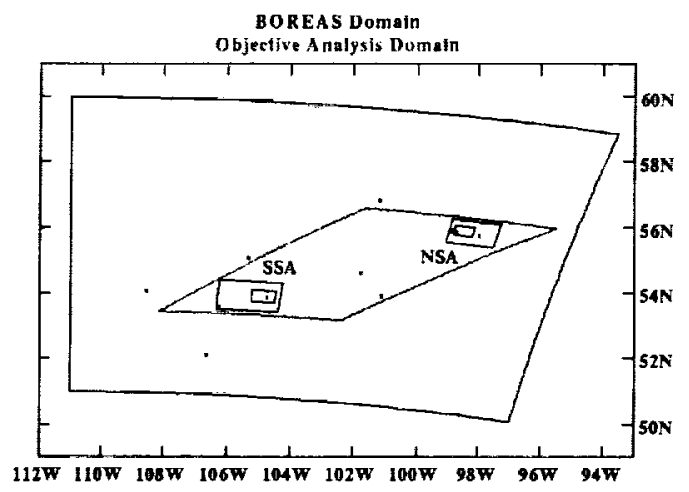

\subsubsection{Spatial Resolution}

The spatial resolution of the gridded data is $5 \mathrm{~km} \mathrm{E-W}$ and $5 \mathrm{~km} \mathrm{~N}-\mathrm{S}$. The spatial resolution for the GOES imagery is nominally $1 \mathrm{~km}$.

\subsubsection{Projection}

The area mapped is projected in the BOREAS Grid projection, which is based on the ellipsoidal version of the Albers Equal-Area Conic (AEAC) projection. The projection has the following parameters:

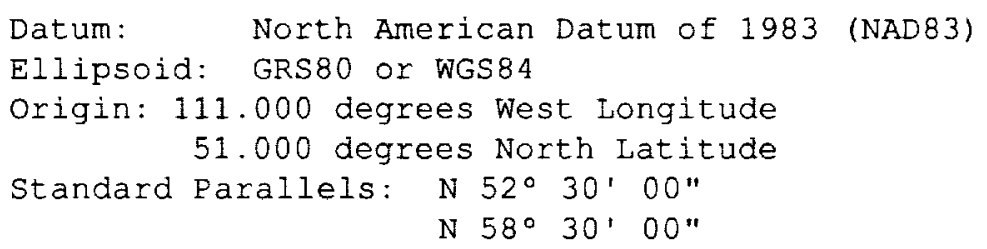

\subsubsection{Grid Description}

The data are gridded in 5-km intervals based on the projection given in Section 7.1.4.

\subsection{Temporal Characteristics}

\subsubsection{Temporal Coverage}

This data set contains continuous data from 16-May-1994 to 20-September-1994; it includes the three summer IFCs:

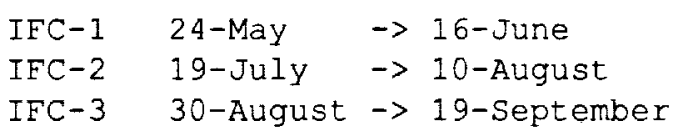




\subsubsection{Temporal Coverage Map}

RSS-14 personnel were at each AMS site during 1994 IFC-2 collecting calibration data for the following days:

$\begin{array}{lccc}\text { AMS SITE } & \text { SITE } & \text { ARRIVE DATE } & \text { DEPARTING DATE } \\ \text { Saskatoon } & \text { SK } & 19 \text { July } & 22 \text { July } \\ \text { Meadow Lake } & \text { MD } & 19 \text { July } & 21 \text { July } \\ \text { Nipawin } & \text { NP } & 23 \text { July } & 24 \text { July } \\ \text { Prince Albert } & & & \\ \quad \text { National Park } & \text { PA } & 24 \text { July } & 26 \text { July } \\ \text { La Ronge } & \text { LR } & 27 \text { July } & 30 \text { July } \\ \text { Flin Flon } & \text { FF } & 30 \text { July } & 01 \text { August } \\ \text { The Pas } & \text { TP } & 30 \text { July } & 01 \text { August } \\ \text { Thompson Airport } & \text { TH } & 01 \text { August } & 04 \text { August } \\ \text { Nelson House } & \text { NL } & 04 \text { August } & 08 \text { August } \\ \text { Lynn Lake } & \text { LL } & 06 \text { August } & 07 \text { August }\end{array}$

\subsubsection{Temporal Resolution}

The data are 30-minute averages. The AMS data were originally reported as 15-minute averages, but because the satellite data are collected every 30 minutes (on the hour and half-hour), this data set is comprises 30 -minute averages.

\subsection{Data Characteristics}

\subsubsection{Parameter/Variable}

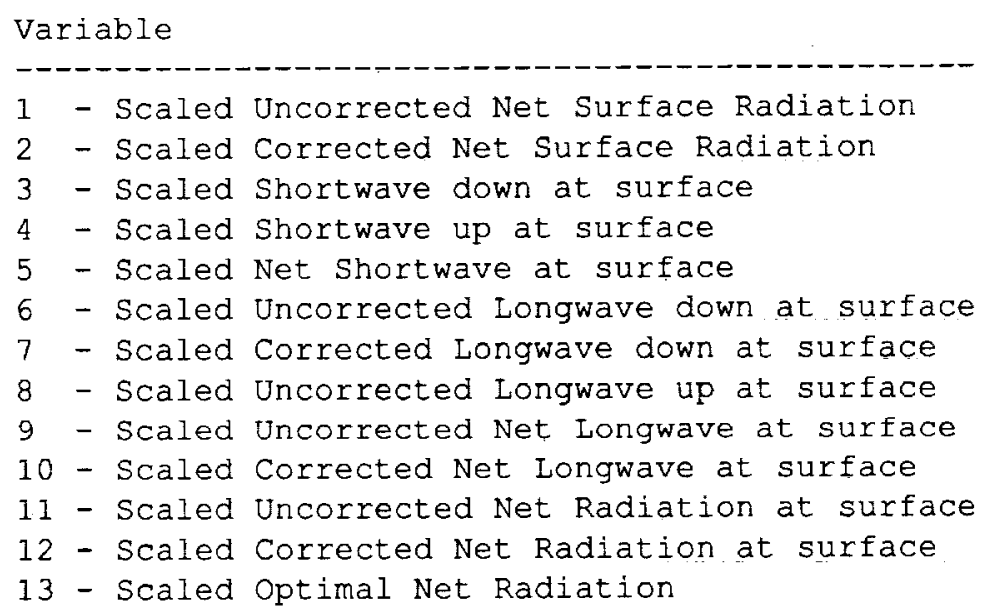

\subsubsection{Variable Description/Definition}

Variable

1 - Scaled Uncorrected Net Surface Radiation
2 - Scaled Corrected Net Surface Radiation
3 - Scaled Shortwave down at surface
4 - Scaled Shortwave up at surface
5 - Scaled Net Shortwave at surface
6 - Scaled Uncorrected Longwave down at surface
7 - Scaled Corrected Longwave down at surface

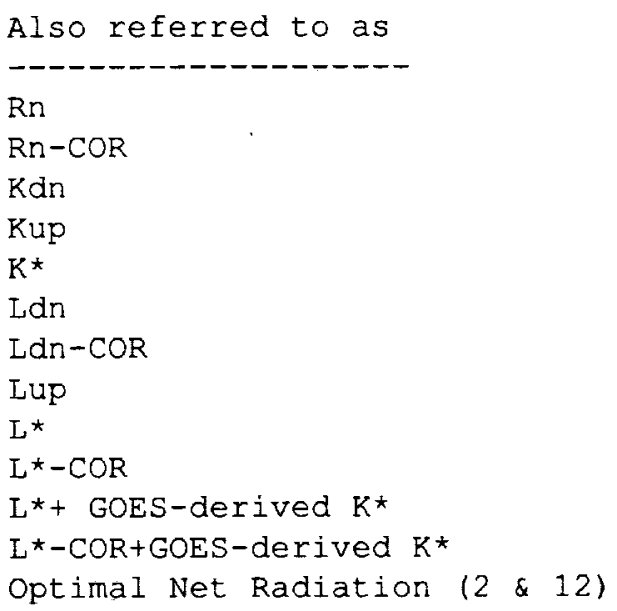


8 - Scaled Uncorrected Longwave up at surface

9 - Scaled Uncorrected Net Longwave at surface

10 - Scaled Corrected Net Longwave at surface

11 - Scaled Uncorrected Net Radiation at surface

12 - Scaled Corrected Net Radiation at surface

13 - Scaled optimal Net Radiation
(4.0 to $100.0 \mu \mathrm{m})$

(4.0 to $100.0 \mu \mathrm{m}$ )

(4.0 to $100.0 \mu \mathrm{m})$

(0.3 to $100.0 \mu \mathrm{m})$

$(0.3$ to $100.0 \mu \mathrm{m})$

$(0.3$ to $100.0 \mu \mathrm{m})$

\subsubsection{Unit of Measurement}

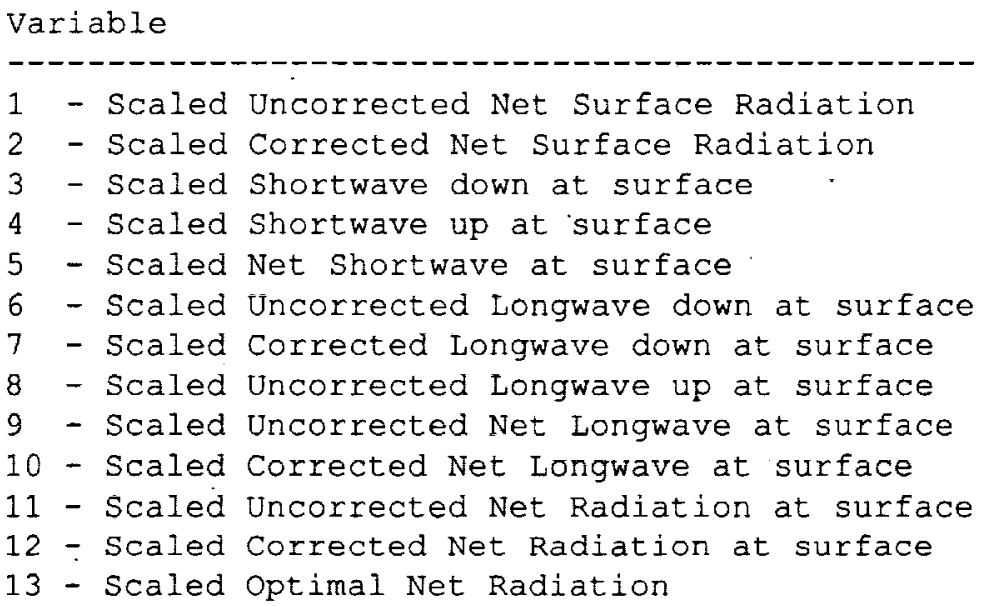

\subsubsection{Data Source}

$$
\begin{aligned}
& \text { Units } \\
& \left.\hdashline 0.1 \mathrm{~W} / \mathrm{m}^{2}\right] \\
& {\left[0.1 \mathrm{~W} / \mathrm{m}^{2}\right]} \\
& {\left[0.1 \mathrm{~W} / \mathrm{m}^{2}\right]} \\
& {\left[0.1 \mathrm{~W} / \mathrm{m}^{2}\right]} \\
& {\left[0.1 \mathrm{~W} / \mathrm{m}^{2}\right]} \\
& {\left[0.1 \mathrm{~W} / \mathrm{m}^{2}\right]} \\
& {\left[0.1 \mathrm{~W} / \mathrm{m}^{2}\right]} \\
& {\left[0.1 \mathrm{~W} / \mathrm{m}^{2}\right]} \\
& {\left[0.1 \mathrm{~W} / \mathrm{m}^{2}\right]} \\
& {\left[0.1 \mathrm{~W} / \mathrm{m}^{2}\right]} \\
& {\left[0.1 \mathrm{~W} / \mathrm{m}^{2}\right]} \\
& {\left[0.1 \mathrm{~W} / \mathrm{m}^{2}\right]} \\
& {\left[0.1 \mathrm{~W} / \mathrm{m}^{2}\right]}
\end{aligned}
$$

\begin{tabular}{|c|c|c|}
\hline Var & riable & Source \\
\hline--- & - - - - - - - - & ------ \\
\hline 1 & - Scaled Uncorrected Net Surface Radiation & AMS \\
\hline 2 & - Scaled Corrected Net Surface Radiation & AMS * \\
\hline 3 & - Scaled Shortwave down at surface & AMS \\
\hline 4 & - Scaled shortwave up at surface & AMS \\
\hline 5 & - Scaled Net Shortwave at surface & AMS \\
\hline 6 & - Scaled Uncorrected Longwave down at surface & AMS \\
\hline 7 & - Scaled Corrected Longwave down at surface & AMS * \\
\hline 8 & - Scaled Uncorrected Longwave up at surface & AMS \\
\hline 9 & - Scaled Uncorrected Net Longwave at surface & AMS \\
\hline 10 & - Scaled Corrected Net Longwave at surface & AMS * \\
\hline 11 & - Scaled Uncorrected Net Radiation at surface & AMS@ \\
\hline 12 & - Scaled Corrected Net Radiation at surface & AMS\& \\
\hline 13 & - Scaled Optimal Net Radiation & AMS * \& \\
\hline $\begin{array}{ll}\star & I \\
0 & S\end{array}$ & $\begin{array}{l}\text { Indicates data were first adjusted according to the ca } \\
\text { Source also includes net solar radiation derived from }\end{array}$ & $\begin{array}{l}\text { alibrations cor } \\
\text { GoEs imagery }\end{array}$ \\
\hline$S$ & Source also includes net solar radiation derived from & GOES imagery, and \\
\hline
\end{tabular}




\subsubsection{Data Range}

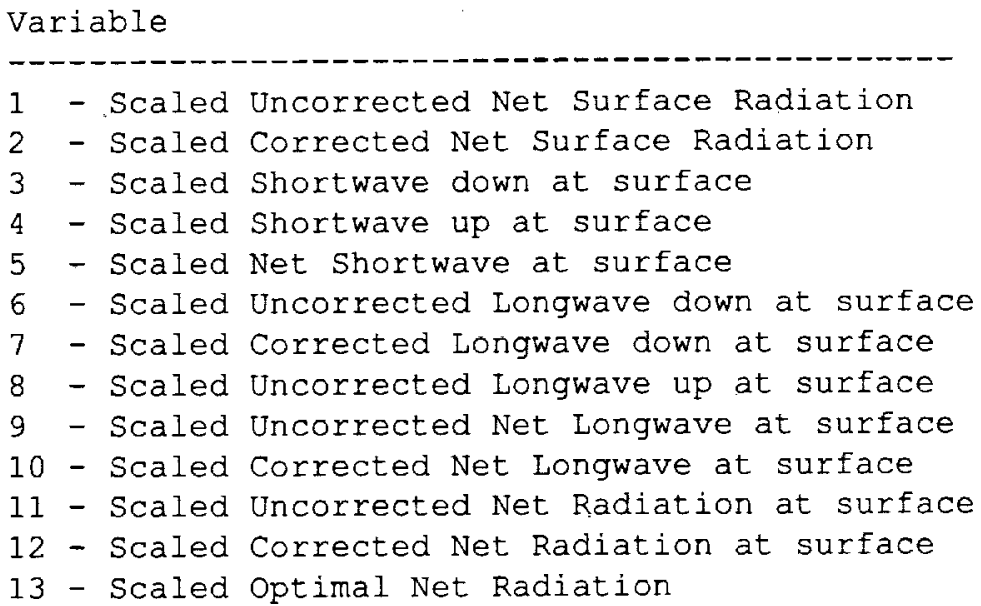



\subsection{Sample Data Record}

The following is a sample header from one of the image data files:






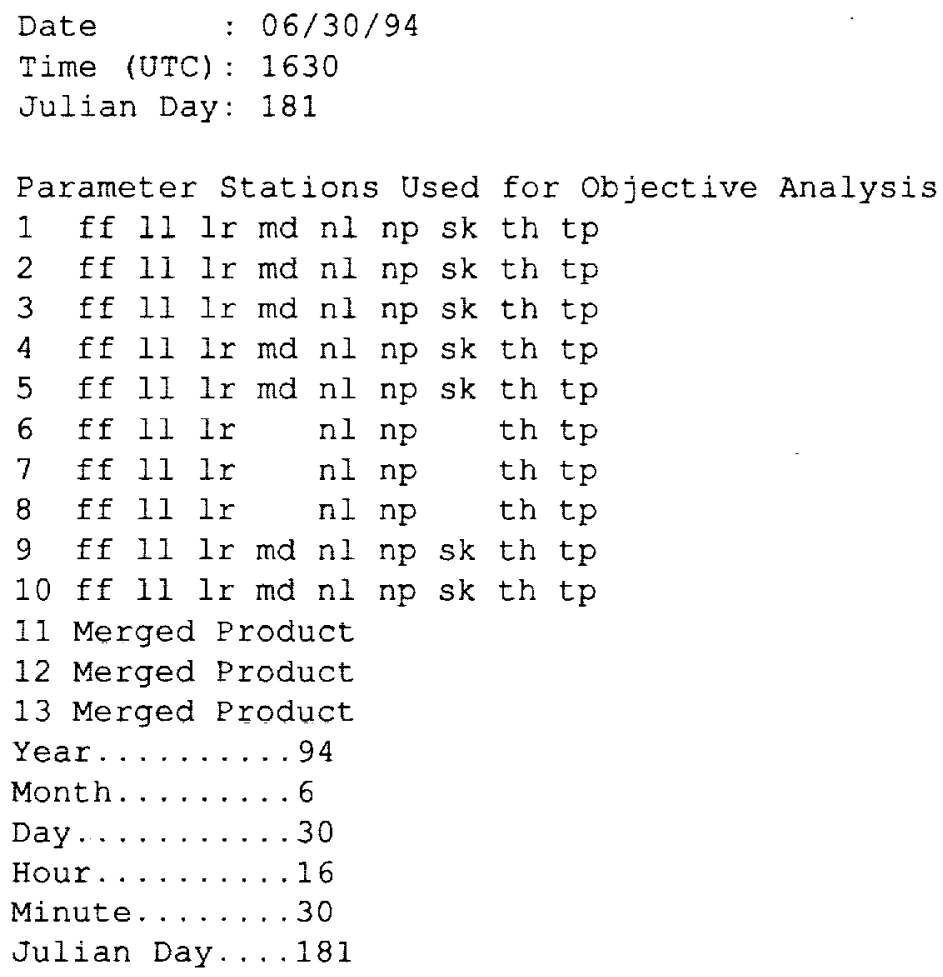

In the above header record under "Parameter Stations Used for Objective Analysis," the station "pa" is not reporting for any parameter at that time. The station abbreviations stand for:

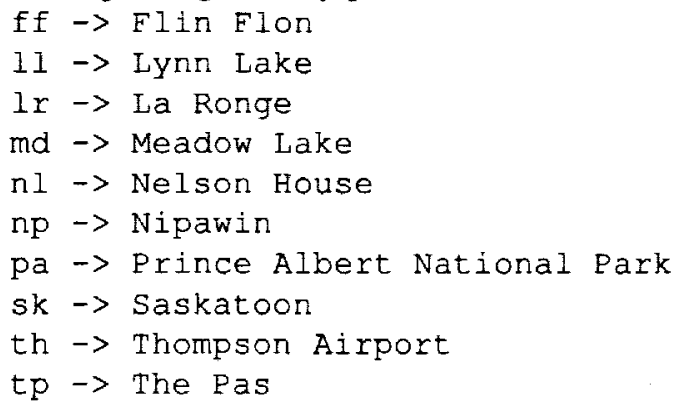

To clarify, if a station abbreviation is listed under "Parameter Stations Used for Objective Analysis," that particular station is reporting that value at that time step. There was no minimum number of reporting stations for the objective analysis to run, rather it is up to the end user of these data to determine whether there are enough stations present to produce a good analysis. 


\section{Data Organization}

\subsection{Data Granularity}

The smallest orderable unit of data is one day's worth of data, which would consist of 48 data files, one for each 30-minute period.

\subsection{Data Format}

\subsubsection{Uncompressed Format}

All the gridded radiation image data are stored in 6,144 files (48 files/day * 128 days). Each file contains 14 records of 12,168 bytes. The first record is an ASCII header record. Records 2-14 are a series of 13 image parameters for a given 30-minute time period. The series of records in the file are:

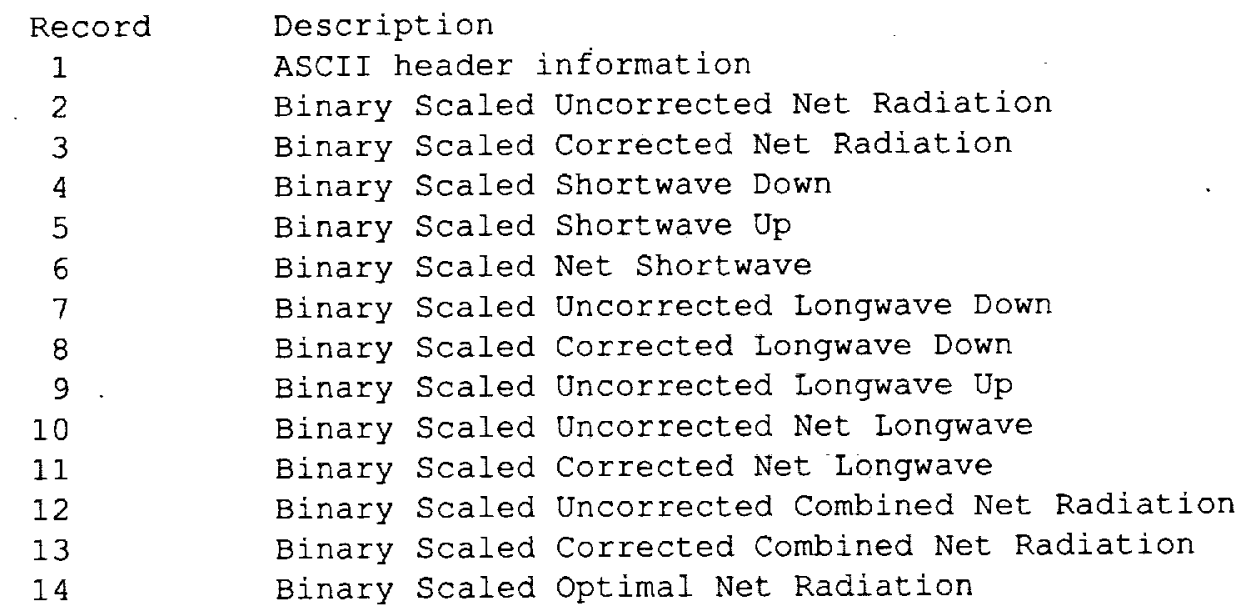

The ASCII header record contains 156 logical records of 78 bytes each.

Records 2 to 13 each contain 78 logical records (image lines) of 156 bytes. Each image line contains 78 2-byte (16-bit) values that represent the 78 pixels across the line. The 2-byte values are stored as low-order byte first. Software to read the files can be obtained by anonymous ftp at: metsat.met.fsu.edu in boreas/Station_grid_products

\subsubsection{Compressed Format}

The image files been compressed with the Gzip (GNU zip) compression program (file_name.gz). These data have been compressed using gzip version 1.2.4 and the high compression (-9) option (Copyright (C) 1992-1993 Jean-loup Gailly). Gzip uses the Lempel-Ziv algorithm (Welch, 1994) also used in the zip and PKZIP programs. The compressed files may be uncompressed using gzip (with the -d option) or gunzip. Gzip is available from many Web sites (for example, the ftp site prep.ai.mit.edu/pub/gnu/gzip-*.*) for a variety of operating systems in both executable and source code form. Versions of the decompression software for various systems are included on the CD-ROMs. 


\section{Data Manipulations}

\subsection{Formulae}

Only AMS data were used. Those parameters that DO NOT include a "-COR" were taken directly from the AMS data base and were not altered in any way. For example, parameter Rn is the direct measurement of net radiation at all the sites, interpolated onto the standard BOREAS grid. Those parameters that DO contain the designation "-COR" have been altered before being interpolated onto the grid. For example, to get Rn-COR, the Rn data set at each site first had the calibrations applied and then were interpolated onto the grid. Similarly, $\mathrm{L}^{*}$-COR was extracted from $\mathrm{Rn}$-COR by subtracting $\mathrm{K}^{*}$, i.e., $\mathrm{L} *$-COR $=\mathrm{Rn}-\mathrm{COR}-\mathrm{K}^{*}$.

Parameters 11 and 12 (Records 12 and 13) are GOES-based values of net radiation. That is, using $\mathrm{L}^{*}$ extracted from the net radiation measurements and adding this to $\mathrm{K}^{*}$ derived from GOES satellite imagery results in a GOES-based field of net radiation. Direct measurements of $\mathrm{L}^{*}$ were not used because too few of the sites were measuring downwelling or emitted longwave radiation to produce good results during the objective analysis.

Parameter 13 (Record 14) is what is known as "Optimal Net Radiation." This parameter was arrived at by fusing parameters 2 and 12 (Records 3 and 13). The idea behind this parameter is that it will combine the optimal properties of the two parameters, thereby producing an optimal field. The fusing process provides more weight to parameter 2 (Record 3 ) at grid points close to a measurement site. The weighting scheme gives progressively larger weights to parameter 12 (Record 13) as the distance from a measurement site increases, and vice versa for parameter 2 (Record 3 ). The corrected measurements of $\mathrm{Rn}$ in the direct vicinity of each AMS site are more accurate than the GOES-based estimates of $\mathrm{Rn}$ at the same location. However, the GOES-based measurements better represent the between-site gradients of the net radiation field. By combining the two parameters with a distance-based weighting function, it is hoped that an optimal field (in both gradient and measurement accuracy) is produced.

$$
\begin{aligned}
& \mathrm{Rn}=\mathrm{K}^{*}+\mathrm{L}^{*} \text { net_radiation }=\text { net_shortwave_radiation }+ \text { net_longwave_radiation } \\
& \mathrm{K}^{*}=\mathrm{K} \text { _down }-\mathrm{K} \text { _up } \\
& \mathrm{L}^{*}=\mathrm{L} \text { _down }-\mathrm{L} \text { _up }
\end{aligned}
$$

Upwelling longwave radiation was calculated from the surface temperature retrieved from the Everest/4000 IRT using the following equation:

$$
\mathrm{I}=\mathrm{e}^{*} \mathrm{~s} * \mathrm{~T}^{4} \quad \text { (Stefan-Boltzmann Law) }
$$

where $\mathrm{e}=$ emissivity

$$
\mathrm{s}=\text { Stefan-Boltzmann constant }
$$

$\mathrm{T}=$ temperature

$\mathrm{K}$ _down = incoming solar radiation

$\mathrm{K} \_$up $=$reflected solar radiation

L_down = downwelling longwave radiation (emitted by atmosphere)

L_up =upwelling longwave radiation (emitted by Earth)

\subsubsection{Derivation Techniques and Algorithms}

No special derivation techniques or algorithms were used. 


\subsection{Data Processing Sequence}

\subsubsection{Processing Steps}

- All the AMS net radiometers were calibrated.

- The new calibrations were applied to the AMS Rn data set for IFC-1, 2, and 3.

- $\quad L^{*}$ was extracted from the Rn values (and corrected $\mathrm{Rn}$ values).

- Other AMS radiation parameters, such as K_down and K_up, were retrieved.

- GOES-retrieved values of $\mathrm{K}^{*}$ were combined with $\mathrm{L}^{*}$ to produce a new $\mathrm{Rn}$.

- An objective analysis procedure was applied to the data.

- The gridded data sets were then converted to binary format.

NOTE: Objective Analysis Procedure

The objective analysis scheme incorporates a weighting function based on the distance d(i) of any given measuring site $i$ to any grid point. The weights assigned to the individual net pyrradiometer measurements are based on the inverse squares of the d(i)'s; i.e., the set of weights is given by the set of all d(i)-2. Thus, at each grid point, the objective analysis scheme calculates a weighted average value for that point based on all surrounding net radiation measurements within a cutoff distance $\mathrm{d}(\mathrm{max})$, using the inverse distance-square station weights. Closer stations thus get the largest weights. A grid mesh of $5 \mathrm{~km}$ was selected and the $\mathrm{d}(\max )$ parameter assigned to $100 \mathrm{~km}$. Sensitivity tests were performed by removing various stations and reanalyzing and by doing so with different sizes for $\mathrm{d}(\max )$. These tests demonstrate that the resultant objectively analyzed fields are not particularly sensitive to changes in the analysis design. Subjective (hand) analyses of the net radiation field were also compared with results from the computer analysis. Both sets of analyses were in close agreement. These tests indicate that the interpretation of the intercomparison results should not be meaningfully affected by the objective analysis design.

BOREAS Information System (BORIS) personnel processed the data by:

- Extracting and verifying header information from each file to inventory the data in the online data base.

- Compressing the files for distribution on CD-ROM.

\subsubsection{Processing Changes}

No noteworthy processing changes were made.

\subsection{Calculations}

\subsubsection{Special Corrections/Adjustments}

The 15-minute average AMS data had to be averaged to 30 minutes to be compatible with the satellite images, which are available only on the hour and half-hour.

\subsubsection{Calculated Variables}

Parameters 12 and 13 (the merged, or optimal, products) were the only calculated variables. A weighting function, based strictly on distance from the nearest AMS station, was used for the calculation(s). For a grid point at or very near an AMS station, the value is essentially the value measured at the station. As the distance from the station increases, the weighting of the satellite-based value of net radiation increases and the weighting of the point measurement, or value measured at the nearest AMS site, decreases.

\subsection{Graphs and Plots \\ None.}




\section{Errors}

\subsection{Sources of Error}

There are a few things users should be cognizant of before using these data:

- The pre- and post-field calibrations of the transfer instruments varied on the order of 5\%. It is not known if this change is the result of an actual calibration drift or the result of differing atmospheric conditions during the pre- and post-field calibrations. Even with these changes, these calibrations are still believed to be an improvement.

- The satellite-based values of net radiation are a combination of $L^{*}$ extracted from net pyrradiometer measurements of net radiation and satellite-retrieved values of net solar radiation. Hodges and Smith (1997) examined only the hours around solar noon (+/- 3 hours around solar noon). This reduced errors from the combination of the two data sets since $\mathrm{L}^{*}$ is typically $10 \%$ of $\mathrm{K}^{*}$ at these times. However, for this data set, the satellite-based values are available from sunrise to sunset (nighttime values of the satellite-based measurements are only net pyrradiometer measurements of net radiation).

- One must also realize that the satellite-based values of net radiation are a combination of 30-minute averaged data $\left(\mathrm{L}^{*}\right)$ and instantaneous snapshots of the conditions on the hour and half-hour. On a clear day, errors resulting from this combination will be small; however, under cloudy or convective conditions, errors could be significant.

- While at the Lynn Lake AMS site, the AMS datalogger was not operating as a result of lightning prior to the team's arrival. As a result, a calibration factor was not found for this site's instrument. For the corrected parameters in this data set (such as Rn-COR), an average correction was used for the Lynn Lake data. That is, the correction factors at the nine other AMS sites were averaged to produce a correction factor for Lynn Lake.

- Users of this data set should be cognizant of the "Parameter Stations Used for Objective Analysis" section in each file header. In the end, it was decided in the creation of this data set NOT to include a minimum number of stations required for the objective analysis to run, but instead, to have it run no matter how many stations were reporting and to provide a list of the reporting stations. This way the user can decide for him or herself whether a missing station(s) will affect the analysis.

\subsection{Quality Assessment}

\subsubsection{Data Validation by Source}

Because no other gridded data sets of these fields were available at the time of their creation, no comparisons of the gridded fields were done. Extensive validation has been done with the surface net solar algorithm used to retrieve surface fluxes from GOES data with ground measurements. The interested reader should consult Gu and Smith (1997) for these details.

Subjective (hand) analyses at several time steps were compared with the results of the objective analysis, with very good agreement.

\subsubsection{Confidence Level/Accuracy Judgment}

Overall, satisfaction with this data set is pretty good. What a person should keep in mind, however, is the inaccuracy of the net pyrradiometers themselves. RSS-14 is confident that the calibrations performed improved the accuracy of the measurements, but how close they are to being "correct" is unknown. At the very least, they all were calibrated to a single source instead of all having independent calibrations. (Smith, et. al., 1997, have shown that the percentage spread in measured values can vary substantially when the original factor calibrations are used.)

\subsubsection{Measurement Error for Parameters}

At this time, quantitative errors cannot be placed on the data set. Because the "real" values of net radiation are just not known, it is necessary to wait for the reaction of modelers to the data set to see if in fact these data are an improvement. 


\subsubsection{Additional Quality Assessments}

None given.

\subsubsection{Data Verification by Bata Center}

BORIS personnel used developed software to extract and verify the descriptive information provided with the images. A random selection of the image files were reviewed visually to verify that the data appeared to be correct.

\section{an \\ 11. Notes}

\subsection{Limitations of the Data}

Users should be careful about using data near the boundaries, especially in the NE portion (which includes some of the NSA), since portions are outside of the domain of the AMS network and extrapolation errors are likely greater in this region.

\subsection{Known Problems with the Data}

There are no known problems per se; however, one should be cognizant of the issues discussed in Section 10.

\subsection{Usage Guidance}

$$
\text { ro } \times \text { s }
$$

Users should proceed with caution, and understand the discussion in Section 10.1. Before uncompressing the Gzip files on CD-ROM, be sure that you have enough disk space to hold the uncompressed data files. Then use the appropriate decompression program provided on the CD-ROM for your specific system.

\subsection{Other Relevant Information}

None given.

TI

\section{Application of the Data Set}

Energy budget modelers should find this data set useful, especially if they are interested in between-site values.

$e^{2}$

\section{Future Modifications and Plans}

No future updates or módifications are planned for these data.

$$
\text { niii }
$$

\section{Software}

\subsection{Software Description}

Software is available to assist in reading the files. Gzip (GNU zip) uses the Lempel-Ziv algorithm (Welch, 1994) used in the zip and PKZIP commands.

\subsection{Software Access}

Software for reading the data is available by anonymous ftp at metsat.met.fsu.edu in boreas/Station_grid_products. Gzip is available from many Web sites across the Internet (for example, $\mathrm{ftp}$ site prep.ai.mit.edu/pub/gnu/gzip-*.*) for a variety of operating systems in both executable and source code form. Versions of the decompression software for various systems are included on the CD-ROMs. 


\section{Data Access}

The level-3 gridded radiometer and satellite surface radiation images are available from the Earth Observing System Data and Information System (EOSDIS) Oak Ridge National Laboratory (ORNL) Distributed Active Archive Center (DAAC).

\subsection{Contact Information}

For BOREAS data and documentation please contact:

ORNL DAAC User Services

Oak Ridge National Laboratory

P.O. Box 2008 MS-6407

Oak Ridge, TN 37831-6407

Phone: (423) 241-3952

Fax: (423) 574-4665

E-mail: omldaac@ornl.gov or oml@eos.nasa.gov

\subsection{Data Center Identification}

Earth Observing System Data and Information System (EOSDIS) Oak Ridge National Laboratory (ORNL) Distributed Active Archive Center (DAAC) for Biogeochemical Dynamics http://www-eosdis.ornl.gov/.

\subsection{Procedures for Obtaining Data}

Users may obtain data directly through the ORNL DAAC online search and order system [http://www-eosdis.ornl.gov/] and the anonymous FTP site [ftp://www-eosdis.ornl.gov/data/] or by contacting User Services by electronic mail, telephone, fax, letter, or personal visit using the contact information in Section 15.1.

\subsection{Data Center Status/Plans}

The ORNL DAAC is the primary source for BOREAS field measurement, image, GIS, and hardcopy data products. The BOREAS CD-ROM and data referenced or listed in inventories on the CD-ROM are available from the ORNL DAAC.

\section{Output Products and Availability}

\subsection{Tape Products}

This data set is available on $8-\mathrm{mm}$ or Digital Archive Tape (DAT) media.

\subsection{Film Products}

None.

\subsection{Other Products}

These data are available on the BOREAS CD-ROM series. 


\section{References}

\subsection{Platform/Sensor/Instrument/Data Processing Documentation}

Radiation and Energy Balance Systems, Inc. Q*6 Instruction Manual.

The Eppley Laboratory, Inc. Instruction Manuals for the PSP, PIR, and Everest IRT.

Welch, T.A. 1984. A Technique for High Performance Data Compression. IEEE Computer, Vol. 17, No. 6, pp. 8-19.

\subsection{Journal Articles and Study Reports}

Gu, J. and E.A. Smith. 1997. High-resolution estimates of total solar and PAR surface fluxes over large-scale BOREAS study area from GOES measurements. Journal of Geophysical Research 102(D24):29,685-29,705.

Hodges, G.B. 1997. Synthesis of BOREAS surface net radiation measurements. M.S. Thesis, Dept. of Meteorology, Florida State University, $68 \mathrm{pp}$.

Hodges, G.B. and E.A. Smith. 1996. Optimal estimates of surface net radiation field over BOREAS study-area from combination of net radiometer point measurements and GOES satellite retrievals. Eighth Conf. on Sat. Met. \& Ocean. Amer. Met. Soc., Boston, MA. pp. 464-465.

Hodges, G.B. and E.A. Smith. 1997. Intercalibration, objective analysis, intercomparison and synthesis of BOREAS surface net radiation measurements. Journal of Geophysical Research 102(D24):28,885-28,900.

Newcomer, J., D. Landis, S. Conrad, S. Curd, K. Huemmrich, D. Knapp, A. Morrell, J. Nickeson, A. Papagno, D. Rinker, R. Strub, T. Twine, F. Hall, and P. Sellers, eds. 2000. Collected Data of The Boreal Ecosystem-Atmosphere Study. NASA. CD-ROM.

Sellers, P. and F. Hall. 1994. Boreal Ecosystem-Atmosphere Study: Experiment Plan. Version 1994-3.0, NASA BOREAS Report (EXPLAN 94).

Sellers, P. and F. Hall. 1996. Boreal Ecosystem-Atmosphere Study: Experiment Plan. Version 1996-2.0, NASA BOREAS Report (EXPLAN 96).

Sellers, P., F. Hall, and K.F. Huemmrich. 1996. Boreal Ecosystem-Atmosphere Study: 1994 Operations. NASA BOREAS Report (OPS DOC 94).

Sellers, P., F. Hall, and K.F. Huemmrich. 1997. Boreal Ecosystem-Atmosphere Study: 1996 Operations. NASA BOREAS Report (OPS DOC 96).

Sellers, P., F. Hall, H. Margolis, B. Kelly, D. Baldocchi, G. den Hartog, J. Cihlar, M.G. Ryan, B. Goodison, P. Crill, K.J. Ranson, D. Lettenmaier, and D.E. Wickland. 1995. The boreal ecosystem-atmosphere study (BOREAS): an overview and early results from the 1994 field year. Bulletin of the American Meteorological Society. 76(9):1549-1577.

Sellers, P.J., F.G. Hall, R.D. Kelly, A. Black, D. Baldocchi, J. Berry, M. Ryan, K.J. Ranson, P.M. Crill, D.P. Lettenmaier, H. Margolis, J. Cihlar, J. Newcomer, D. Fitzjarrald, P.G. Jarvis, S.T. Gower, D. Halliwell, D. Williams, B. Goodison, D.E. Wickland, and F.E. Guertin. 1997. BOREAS in 1997: Experiment Overview, Scientific Results and Future Directions. Journal of Geophysical Research 102(D24): 28,731-28,770. 
Smith, E.A., G.B. Hodges, M. Bacrania, H.J. Cooper, M.A. Owens, R. Chappell, and W. Kincannon. 1997. BOREAS net radiometer engineering study. NASA Report under Grant NAG5-2447.

\subsection{Archive/DBMS Usage Documentation None.}

\section{Glossary of Terms}

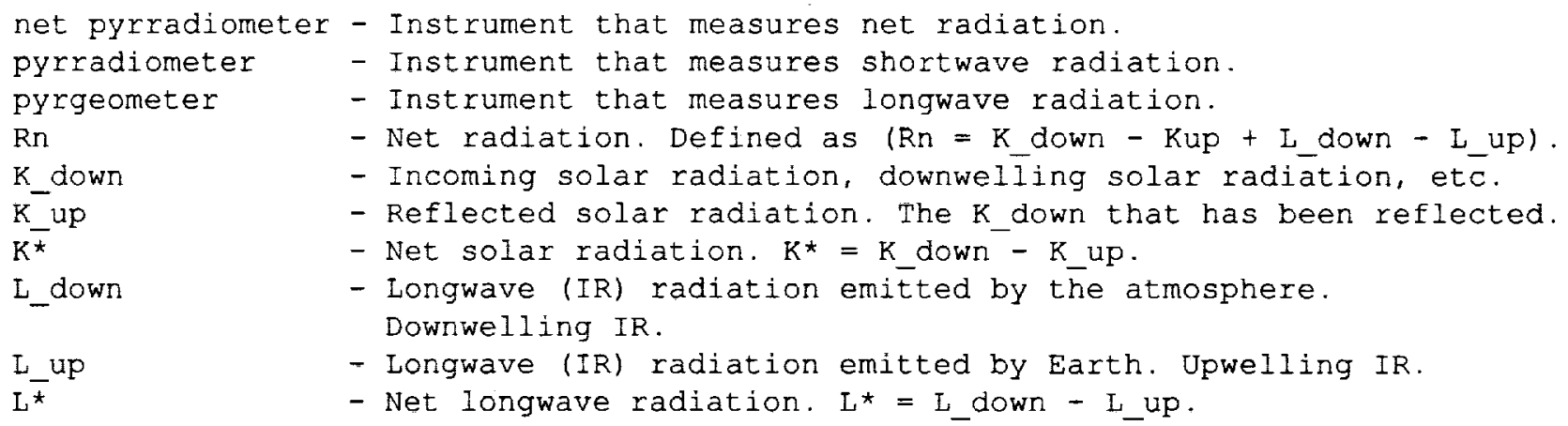

\section{List of Acronyms}






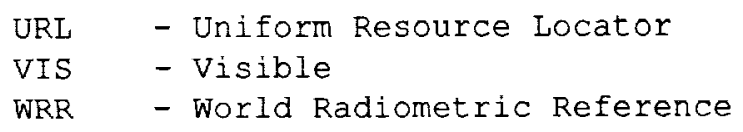

\section{Document Information}

20.1 Document Revision Date(s)

Written: 22-Dec-1997

Last Updated: 06-Aug-1999

20.2 Document Review Date(s)

BORIS Review: 16-Jan-1998

Science Review:

\subsection{Document ID}

\subsection{Citation}

Dr. Eric A. Smith, Dept. of Meteorology, Florida State University, should be acknowledged when this data set is referenced or used by another investigator. Additionally, the following papers should be cited as well as any other relevant papers in Section 17.2:

Gu, J. and E.A. Smith. 1997. High-resolution estimates of total solar and PAR surface fluxes over large-scale BOREAS study area from GOES measurements. Journal of Geophysical Research 102(D24):29,685-29,705.

Hodges, G.B. and E.A. Smith. 1997. Intercalibration, objective analysis, intercomparison and synthesis of BOREAS surface net radiation measurements. Joumal of Geophysical Research 102(D24):28,885-28,900.

If using data from the BOREAS CD-ROM series, also reference the data as:

Smith, E.A., "Quality Assurance of BOREAS Net Radiation Measurements." In Collected Data of The Boreal Ecosystem-Atmosphere Study. Eds. J. Newcomer, D. Landis, S. Conrad, S. Curd, K. Huemmrich, D. Knapp, A. Morrell, J. Nickeson, A. Papagno, D. Rinker, R. Strub, T. Twine, F. Hall, and P. Sellers. CD-ROM. NASA, 2000.

Also, cite the BOREAS CD-ROM set as:

Newcomer, J., D. Landis, S. Conrad, S. Curd, K. Huemmrich, D. Knapp, A. Morrell, J.

Nickeson, A. Papagno, D. Rinker, R. Strub, T. Twine, F. Hall, and P. Sellers, eds. Collected Data of The Boreal Ecosystem-Atmosphere Study. NASA. CD-ROM. NASA, 2000.

\subsection{Document Curator}

\subsection{Document URL}


Public reporting burden for this collection of information is estimated to average 1 hour per resportse, including the time for revlewing instructions, searching existing data sources gathering and maintaining the data needed, and completing and reviewing the collection of information. Send comments regarding this burden estimate or any other aspect of this collection of information, including suggestions for reducing this burden, to Washington Headquarters Services, Directorate for Information Operations and Heports, 1215 Jefferson Davis Hlghway, Suite 1204, Arlington, VA 22202-4302, and to the Office of Management and Budget. Paperwork Reduction Project (0704-0188), Washington, DC 20503.
1. AGENCY USE ONLY (Leave blank)
2. REPORT DATE
3. REPORT TYPE AND DATES COVERED
August 2000
Technical Memorandum

4. TITLE AND SUBTITLE

Technical Report Series on the Boreal Ecosystem-Atmosphere Study (BOREAS)

BOREAS RSS-14 Level-3 Gridded Radiometer and Satellite Surface

Radiation Images

6. AUTHOR(S)

Gary Hodges and Eric A. Smith

Forrest G. Hall and Jaime Nickeson, Editors

7. PERFORMING ORGANIZATION NAME(S) AND ADDRESS (ES)

Goddard Space Flight Center

Greenbelt, Maryland 20771

923

RTOP: $923-462-33-01$

9. SPONSORING / MONITORING AGENCY NAME(S) AND ADDRESS (ES)

10. SPONSORING / MONITORING AGENCY REPORT NUMBER

National Aeronautics and Space Administration

TM-2000-209891

Washington, DC 20546-0001

Vol. 64

11. SUPPLEMENTARY NOTES

G. Hodges and E.A. Smith: Florida State University; J. Nickeson: Raytheon ITSS

12a. DISTRIBUTION / AVAILABILITY STATEMENT

12b. DISTRIBUTION CODE

Unclassified-Unlimited

Subject Category: 43

Report available from the NASA Center for AeroSpace Information,

7121 Standard Drive, Hanover, MD 21076-1320. (301) 621-0390.

\section{ABSTRACT (Maximum 200 words)}

The BOREAS RSS-14 team collected and processed GOES-7 and -8 images of the BOREAS region as part of its effort to characterize the incoming, reflected, and emitted radiation at regional scales. This data set contains surface radiation parameters, such as net radiation and net solar radiation, that have been interpolated from GOES-7 images and AMS data onto the standard BOREAS mapping grid at a resolution of $5 \mathrm{~km} \mathrm{~N}-\mathrm{S}$ and $\mathrm{E}-\mathrm{W}$. While some parameters are taken directly from the AMS data set, others have been corrected according to calibrations carried out during IFC-2 in 1994. The corrected values as well as the uncorrected values are included. For example, two values of net radiation are provided: an uncorrected value ( $\mathrm{Rn})$, and a value that has been corrected according to the calibrations (Rn-COR). The data are provided in binary image format data files.

Note: some of the data files on the BOREAS CD-ROMs have been compressed using the Gzip program. See section 8.2 for details.

\section{SUBJECT TERMS}

BOREAS, remote sensing science, GOES -7 and -8 , radiation images.

15. NUMBER OF PAGES 21

16. PRICE CODE

17. SECURITY CLASSIFICATION 18. SECURITY CLASSIFICATION OF REPORT

Unclassified OF THIS PAGE

Unclassified

19. SECURITY CLASSIFICATION OF ABSTRACT

Unclassified

20. LIMTIATION OF ABSTRACT

$\mathrm{UL}$ 